\title{
Seeds of Control: Japan's Empire of Forestry in Korea. By David Fedman. Seattle: University of Washington Press, 2020. ix, 292 p [ISBN: 9780295747453]
}

Anne Whitehouse*

Environmental histories of Korea and the Korean landscape remain scant in the English-language scholarly corpus. Studies like David Fedman's Seeds of Control: Japan's Empire of Forestry in Colonial Korea represent some of the first book-length contributions (in English) to this emerging field. Fedman's first monograph makes interdisciplinary contributions that will appeal to scholars across disciplinary frameworks who study forestry, colonialism, the environment, the Japanese Empire, and Korea. The book not only draws attention to imperial forestry in a region that is frequently overlooked in conversations of global environmental history and colonial forestry, but it also reframes conservation as a tool of imperialism, expanding understandings of colonial violence in the Japanese Empire to include silvicultural rhetoric and policy. While Seeds of Control focuses on the Korean peninsula geographically, Fedman's insights about Japanese forestry ideology also inform environmental histories of the "green archipelago" in his exploration of colonial policies of reforestation and assimilation. The arguments made in Seeds of Control

* Anne Whitehouse is an MA candidate in Asian Studies and Environmental Humanities at the University of Utah. Her research interests include urban waterways and modern Korean literature. 
have broad application and interest, which makes this monograph a landmark contribution to the growing body of environmental history, particularly in its focus on the Korean peninsula.

In Seeds of Control, Fedman's core argument is one that centers forestry and silviculture as tools of physical, cultural, and spiritual assimilation. In crafting this argument, Fedman strives to think outside of what he calls "binaries of colonial exploitation and native rehabilitation." The effect of this is not to diminish the impact of colonial violence, but rather to complicate our understandings of how that colonial violence was perpetrated and how it impacted the lives of the colonized (for example, in understanding how reforestation and conservation can be used to control or oppress colonized populations as well as mitigate the effects of deforestation and environmental degradation). In a narrative that challenges common conceptions of colonial rule as monolithic with top-down implementation of a consistent vision, Fedman emphasizes the inconsistencies of the colonial Government-General's vision and administration of colonial forestry in Korea in a story that comes to life through the contingencies of history, the unique qualities of the Korean landscape, and the agency of individuals both Korean and Japanese. Using the archive of the former colonial Bureau of Forestry in Korea as well as police reports, popular literature, and journalistic dispatches, Fedman crafts an engaging history that not only contains useful information and insights, but also is enjoyable to read.

Seeds of Control is divided into three parts, and Part 1, "Roots," details ideologies about forestry and silviculture in the metropole as well as conceptions of the Korean landscape. In Chapter 1, Fedman maps the trialand-error development of forestry policy and management as well as the relationship between silviculture and Japanese identity during the Meiji Period (1868-1912). He argues that this period saw an "imperialization of forestry" in which forests were reinvented as spaces sacred to the emperor and which could be read as symbols of the empire's industrial strength and economic power. A key component of this argument includes the implication that the ideology of airin shisō, or "forest-love thought," was 
based on "invented sylvan traditions" that emerged during the Meiji Period as imperial authority essentially rewrote Japanese traditions to center a reverence for forests in a new forestry that combined ideas and practices from multiple academic disciplines and countries around the world.

While historians of Japan are certainly part of the target audience for this book, Seeds of Control has multidisciplinary goals and appeal in Fedman's intention to not only contribute colonial case studies to Japanese environmental history but also "write Japan's empire into global environmental history" and to "track an alternative trajectory in the evolution of green imperialism." As such, this book would benefit from a bit more contextualization for scholars less familiar with the particulars of Japanese environmental history. For example, this chapter might include more background for how Meiji-era silvicultural ideologies differed from earlier eras in Japanese history by giving more information about the nature of pre-Meiji silviculture. Fedman does explain how contemporary villagers found some Meiji-era changes to be "a betrayal of the very spirit of Tokugawa forestry," but I found his explanation of said Tokugawa forestry to be a little too brief for a scholar relatively unfamiliar with Japanese environmental history. Providing a little more background information of this nature would add context that would make his insightful and compelling argument about the creation of a forestry ideology and culture during the Meiji era even more convincing.

Fedman shifts focus to the Korean peninsula in Chapter 2 through outsiders' descriptions and perceptions of the Korean landscape before formal colonization (1910). Japanese stories about Korean forests were largely narratives of declension that emphasized the red color of deforested Korean mountainsides readily visible from seaports like Pusan in direct contrast with imagery of Japan's lush, green mountains. Japanese rhetoric interpreted the apparently degraded environment in Korea as stagnation of the Chosŏn state and offered narratives of Koreans as lazy, primitive, and morally depraved. At the same time, Japanese surveyors and foresters framed the state of Korean forests as an economic opportunity to reform and reforest the peninsula through the supposedly ecolog- 
ically superior and more modern methods and ideologies of the Japanese Empire. Thus, stories of the Korean landscape were used as justification for colonization by both Japanese and pro-colonization Koreans, and these narratives dismissed or ignored existing Korean conservation practices and traditions. As he makes this argument, Fedman deftly illustrates the contradictions of Japanese interpretations of Korean forests and points out the ecological and environmental differences between Korean and Japanese soils and climate which complicated the literal transplantation of trees and the metaphorical transplantation of silvicultural practices from Japan to Korea.

As in the rest of the book, Fedman's focus is on the Japanese empire as colonial actors, and this intent is made clear in the Introduction. However, his argument that Japanese colonizers ignored existing Korean conservation practices and stories about their own landscape and forests calls for some more direct discussion of these stories in Fedman's own scholarly treatment. Fedman does briefly mention Korean red pine narratives and traditions as well as Chosŏn forestry institutions, and in later chapters he provides additional detail on both. However, in this chapter, including some more information on these and other Korean perspectives of the peninsular landscape before the arrival of the Japanese in the late $19^{\text {th }}$ and early $20^{\text {th }}$ centuries would contextualize his arguments about the perspectives of outsiders like the Japanese and Westerners. This context would not only be helpful for this book's multidisciplinary audience, but it would also serve to increase the ethos of Fedman's argument by giving attention to Korean landscape traditions that Japanese colonizers disregarded.

Part 2, "Reforms," focuses on actual implementation of imperial forestry policy in Korea before wartime (1910-1937). Chapter 3 covers the legal frameworks for colonial forestry through a land tenure system and the forest surveys that established the foundation of those frameworks. Fedman's analysis of colonial rhetoric and forestry law illuminates the Government-General's intent to control those who used Korean forests as well as how they were used. Multiple case studies demonstrate how the land 
tenure system was stacked in favor of Japanese land owners in requiring specific and often hard-to-acquire forms of documentation as proof of claim to a section of forest. After the March $1^{\text {st }}$ Movement (1919) and the relaxation of colonial restrictions in what is known as the period of "cultural rule," the documentation requirements were changed so that many more Koreans were able to make valid claims to forest parcels, but before gaining the title to the land they were required to make an effort at reforestation, the cost of which remained a frequently insurmountable obstacle for Korean farmers. Consequently, while Korean land owners outnumbered Japanese land owners in colonial Korea, individual Korean claims were dwarfed by the large parcels of land owned and leased by Japanese corporations, and most of the land area was under Japanese ownership.

Chapter 3 also goes into more detail on the Chosonn commons and tells the story of pre-modern deforestation as a result of a population boom and the consequent actions of individuals in their efforts to survive, a situation that occurred despite the diligent and aware efforts of Chosonn state forestry policy. However, the colonial narrative blamed deforestation on the ineptitudes and neglect of the Chosŏn forestry system, a narrative which was further used to justify colonization and Japanese control of land usage and ownership. Fedman's treatment of this topic doesn't go much beyond this, but it would make a fruitful starting point for further exploration of pre-colonial Korean forestry.

Readers with some background in the sciences might find Chapter 4 to be particularly fascinating in its coverage of colonial forestry science and research, especially in its telling stories of collaboration between Japanese and Korean scientists like Ishidoya Tsutomu, Chŏng T'ae-hyŏn, and Asakawa Takumi. During the early colonial period, forestry scientists experienced more freedom to pursue various research topics and even tried to integrate Korean culture and history with regenerative forestry. Ishidoya in particular was interested in Korean culture and conducted interdisciplinary studies (including an ethnographic survey of culturally significant Korean trees), and Asakawa diligently studied the Korean language (notable among Japanese settlers) and interacted with countryside farming 
communities, an activity which informed his research and scientific breakthroughs. Chŏng's role was crucial to these inter-cultural and scientific exchanges as his Japanese counterparts asked him to find rare Korean texts on herbalism and to translate Korean botanical names. This kind of collaboration diminished later on as forestry research became more institutionalized and scientists had less freedom to pursue their chosen research topics, but this case study of settler scientists working in collaboration with Korean scientists and even farmers operating under the belief that "the job of the forester was not simply to methodically plaster these mountains with green, [but] to understand how these biomes were intermeshed with the human settlements around them" was nonetheless engrossing. Additionally, the kind of interdisciplinary work that all three of these scientists participated in is not seen much in the hard sciences as the modern period carries on, much less today, making the case study surprisingly inspiring. As Fedman puts it, the interdisciplinary research conducted by these three scientists emphasized that "the longevity of Korea's forests was not solely the product of physiognomy or climate; it was also the outcome of ritual practice and village life," a concept that, along with their scientific findings, challenged colonial convictions that Japanese and Western species would be superior to native Korean tree species in the Korean landscape.

This does not mean that the relationship between Korean and Japanese scientists was unburdened by the colonial power structure or without discrimination; while Chŏng was paid on par with Asakawa-a practice almost unheard of in colonial laboratories - he was frequently underwritten or left out altogether of the credits for the research team's publications. Additionally, the frequently shifting status quo of colonial rule made interdisciplinary collaborations like Chŏng, Ishidoya, and Asakawa's much rarer and more difficult as time passed. Later in the colonial period, Korean forestry students and scientists also found their contributions even more sidelined than Chŏng's, as Fedman reveals in the story of Hyŏn Sinkyu. Forestry science was certainly fraught with colonial power dynamics and injustice, but Fedman's engagingly-written case studies of individual 
scientists and research teams illuminate some of the frequently overlooked dynamics and opportunities of scientific research that came in various stages of colonial rule, characterizing colonial forestry science as an endeavor with mixed outcomes.

Chapter 5 focuses on industrial timber, mostly in Korea's northern old growth forests. Fedman draws attention to forestry's role in the "industrial transformation of northern Korea," a region Koreans had hitherto considered as wild frontier space that, in the colonial context, was reconceived into a "stepping stone for expansion." Not only did northern Korea see heavy deforestation under Japanese colonial rule, but, notably, industrial timber in this region was also a major source of road and railway construction, creating a transportation network that was critical later during wartime mobilization and intensified industrialization. Political tensions also characterized the timber industry in port towns like Sinŭiju, where competition with lumber companies in Andong on the Manchurian side of the Yalu River was influenced by the often-competing interests of two colonial enterprises. The involvement of the Forestry Management Bureau worked to increase the opportunities that would benefit Japanese timber businesses, a move which left smaller operations (many of which were Korean-owned) struggling to stay afloat in a market that privileged larger companies with greater capital. Fedman also discusses northern forestry's crackdown on swidden agriculture, the relocation of thousands of households to allow for logging and industrial development, and the place of Korea's forestry and timber industry within the regional and empire-wide network of lumber supply, demand, and practices.

Readers interested in spirituality and folk religion will find Fedman's brief discussion of the spiritual aspect of Japanese timber practice fascinating. Fedman describes the ceremonial rituals conducted by Japanese raftsmen at the first run of the season, including the offering of prayers to the "water gods" (mizukami) who watched over specific (and dangerous) sections of the Yalu River. Since the spiritual practices of forestry are not the focus of this chapter, this is kept to a mention, but the indication that Japanese laborers connected to the northern Korean landscape and the 
Yalu River via their own spiritual-religious traditions was quite intriguing. This anecdote would potentially make a useful starting point for further research into Japanese stories about and practices in colonized Korean landscapes.

In Chapter 6, Fedman shifts his focus to civic forestry organizations, specifically detailing how colonized Koreans responded to and were affected by the Japanese efforts to compel rather than coerce forest management. While Japanese forestry officials generally saw Chosŏn forestry as a failure, they also used existing Korean structures like imsu (J: rinsō; "parcels of protected forest") and songgye (village-level civic pine associations historically dedicated to managing and conserving pines) as the foundation for the creation of new and "improved" civic forestry organizations. Because Koreans in the countryside tended to see forests as adjunct to agriculture, colonial rhetoric of forestry strove to make connections between forests and the domestic and agricultural realms, emphasizing how forest conservation was not just the work of foresters, but of every housewife, child, and farmer. While these civic forestry associations drew in members to an extent, they were also accompanied by the redistricting of long-standing communities and hefty membership fees, the latter of which inspired protests from Korean villagers. Fedman illustrates these kinds of conflicts well through the Tanch'ŏn case study, in which youth led the charge to protest exorbitant membership fees in local civic forestry organizations as well as restrictions on woodland access for the community. In a movement that engaged farmers, youth leaders, and intellectuals alike - and which also was influenced by these parties' engagements with socialism, nationalism, and agrarianism-Fedman argues that "far from binary conflicts between colonial oppressors and peasant resistors, these disputes were shaped by a variety of actors with multiple, sometimes overlapping agendas." Here again, as he does throughout this book, Fedman's arguments emphasize the complexity of these dramas as they play out on the colonial stage, demonstrating how multiple actors, interests, and contingencies shaped lived realities in this chapter of Korean history. 
In the third and final section, Part 3, "Campaigns," Fedman turns to the wartime era (1937-1945) and tells two stories of social control and colonial assimilation. In a thoroughly enjoyable analysis of colonial forestry rhetoric, Chapter 7 looks at "forest-love thought" (arin shisō) as spiritual assimilation, an angle on the study of Japanese nature-love myth that is hitherto little-explored. Citing Oguma Eiji's framework of "ambivalent sameness" regarding assimilation rhetoric of the Japanese Empire, Fedman expands that "ambivalent sameness" to include an ecological dimension in which Japanese pundits acknowledged a shared environmental tradition in Korea and Japan while simultaneously asserting that Japanese environmental ethics, ideologies, practice, and even plant species were superior to those in Korea. Fedman also reveals contradictions between this sort of rhetoric and reality in pointing out that Korean tree-planting occurred on a larger scale than tree-planting in the metropole. This rhetorical balancing act allowed flexible use based on the needs and interests in a given situation, allowing it to be used in multiple contexts, like forestry, and for a wide range of colonial audiences in Korea and in the metropole. Fedman describes urban tree planting ceremonies, examines the construction and use of spaces like Ch'anggyŏng Botanical Garden and Namsan Park as symbols of urban modernity, and analyzes poems, art, and an exhibition meant to arouse a spirit of forest reverence and conservation duty in viewers. Fedman's detailed description of the Korean Forest Culture Exhibition (Chōsen Sanrin Bunka Tenrankai) is particularly memorable in its vividness and effectively supports his arguments about forest-love thought as colonial assimilation. Fedman argues that the visual and verbal rhetoric employed in these various means of colonial ecological-spiritual assimilation tended to target elites more than the lower classes, but this inundation of pro-conservation, forest-loving rhetoric represented a massive public relations push, an example that informed activities for civic reforestation mobilization back in the metropole and likely in the Japanese empire's other colonies.

Environmental humanities scholars will be intrigued by Fedman's mention of "forest aesthetics" (J: shinrin bigaku), a growing academic disci- 
pline during the colonial period that "inquired into the relationship between forest scenery, individual perception, and collective values." Scholars who wrote on forest aesthetics essentially analyzed what aspects of forests made them beautiful, connecting affect to the forested landscape in a way that acknowledged the importance of sentiment in conservation. While more narrowed in focus, Fedman's description of forest aesthetics evokes lines of inquiry in the growing field of environmental humanities, especially in that scholars of both disciplines hold a conviction in the significance of culture and human emotion in our understanding of the natural world. A comparative study of forest aesthetics and the environmental humanities could be particularly revealing in how ideas about nature and the environment were and continue to be colonized in elusive ways, ways that often become clearer with the passage of time.

Chapter 8 examines physical control of forest resources and policy during wartime mobilization, focusing particularly on how the acceleration of forest harvesting and resource extraction impacted the lived experiences of Koreans on the home front. While many other histories of colonial forestry in Korea focus on heavy deforestation and wholesale devastation of the landscape to the exclusion of everything else, Fedman's narrative qualifies this by indicating that much of this damage occurred after the outbreak of the Second Sino-Japanese War (1937), and the shift to military and industrial development and supply was not part of Japanese forestry officials' earlier plans and policies. Tightening resource restrictions for domestic residents and fuel scarcity worked in tandem with the rhetoric of resource conservation and forest-love thought to enable the transformation of Korea's forests into an "advance military supply base," one that wreaked havoc on the landscape as well as tightened the belts of residents living the "low-temperature lifestyle" (K: chŏon saenghwal; J: teion seikatsu), which implemented fuel rationing and encouraged increased ondol efficiency and alternative fuel usage.

Much ink has been spilt over the more extreme forms of suffering experienced at the hands of the Japanese during World War II (such as sexual slavery), but Fedman directs his focus to some of the more mundane 
forms of colonial violence during wartime that are usually overlooked. Fedman argues convincingly that such smaller-scale forms of violenceprocesses that are often not even recognized as actual violence-merit more scholarly attention than they currently receive. Citing Rob Nixon's landmark work Slow Violence and the Environmentalism of the Poor, which describes this slow violence as "a different kind of violence, a violence that is neither spectacular nor instantaneous, but rather incremental and accretive, its calamitous repercussions playing out across a range of temporal scales," Fedman makes a productive connection between forestry, environmental degradation, and insidious processes of harm and injustice in colonial Korea. ${ }^{1}$

In the conclusion, Fedman spends a few pages on deforestation during the Korean War and the reforestation efforts of Syngman Rhee (Yi Sŭngman) and Park Chung-hee's (Pak Chŏnghŭi) administrations, the latter of which saw much more success than the first. Since it is beyond the scope of this book, the discussion here is not long, but Fedman does point out helpful continuities between colonial forestry and Park Chunghee's forestry, an insight which enables us to view forestry in Park Chung-hee's South Korea as, in many ways, continuous with the methods and policies used during the colonial era, in part simply because the Korean foresters employed learned their trade during the colonial period. Fedman takes care to clarify that reforestation in South Korea did not occur because of colonial structures, but rather points out that when telling environmental stories, including stories of forestry on the Korean peninsula, one must take the long view to understand unique time periods in the context of what came before.

Fedman also makes it clear in the conclusion that he hopes this book can be a step towards including the Japanese Empire in global histories of forest conservation and scholarship of green imperialism, both of which usually leave the Japanese Empire out of their analyses. Additionally,

1 Nixon, Rob. Slow Violence and the Environmentalism of the Poor. (Cambridge: Harvard University Press, 2011), 2. 
Fedman's nuanced analysis shows a complex picture of imperial forestry that reiterates the findings of other scholarship on the Japanese Empirethat colonial governance and policy was not monolithic, not simply enacting a uniform vision from the top down. Because of the unevenness of colonial rule and its propensity to shift goals and tactics based on historical contingencies, truly understanding the effects of colonialism in places like Korea requires an understanding of how people, ideas, and events uniquely interacted to create the conditions of the time. Seeds of Control marks a meaningful contribution to studies of green imperialism, global environmental history, and the history of the Japanese Empire.

For readers looking for environmental histories of the Korean peninsula, this book is but a beginning. Throughout the book's length, the focus is on Japanese forestry, which makes sense given Fedman's goals as well as the political conditions of the early 20th century. However, Fedman also highlights many Korean moments, stories, and ideologies that act as excellent starting points for future research on Korean environmental history, several of which I have mentioned in this review. As such, Seeds of Control is an excellent and self-aware step into a field that is still growing in English-language scholarship, and it can and will act as an invaluable resource to environmental scholars focused on the Korean peninsula.

In the vein of more Korea-focused environmental histories, Fedman is currently collaborating with Eleana Kim (UC - Irvine) and Albert Park (Claremont McKenna College) on an edited volume tentatively titled Forces of Nature, which will compile scholarship on the environmental history and politics of the Korean peninsula. This collection will be the first of its kind in English, and it will be the first in Cornell University Press's open-access book series called Environments of East Asia. ${ }^{2}$ Publication is expected in Fall 2022, and I, for one, eagerly anticipate its release.

2 The February 2020 special theme issue of the International Journal of Korean History was, "New Perspectives from Korean Environmental History." 